Jurnal Pemberdayaan: Publikasi Hasil Pengabdian kepada Masyarakat

Vol. 2, No. 1, April 2018, Hal. 151-158

ISSN: 2088 4559; e-ISSN: XXXX-XXXX

DOI:

\title{
PEMBERDAYAAN MASYARAKAT MELALUI KAMPUNG RAMAH ANAK DI KELURAHAN BACIRO, KECAMATAN GONDOKUSUMAN, KOTA YOGYAKARTA
}

\author{
Rina Ratih, Fahmi Handika Rahmawan \\ Universitas Ahmad Dahlan Yogyakarta \\ rinaratihuad@yahoo.com
}

\begin{abstract}
ABSTRAK
Kampung Gendeng, Kelurahan Baciro, Kecamatan Gondokusuman, termasuk daerah perkotaan di Yogyakarta. Sarana prasarana umumnya pun sudah baik. Permasalahan yang ada pada masyarakat ini adalah kurangnya fasilitas dan perhatian masyarakat terhadap kegiatan berkesenian bagi anak-anak. Maka, program ini bertujuan untuk membangun sebuah sistem pembangunan anak yang lebih terintegrasi dan berkelanjutan dalam dimensi kabupaten/kota menuju kampung ramah anak. Metode pelaksanaan program meliputi pemberian ceramah, praktek, dan pembinaan. Hasil dan dampak dari kegiatan ini adalah pemenuhan hak-hak anak untuk mendapatkan informasi dan pelatihan berkesenian terpenuhi.
\end{abstract}

Kata kunci: pemberdayaan, kesenian, ramah anak

\section{ABSTRACT}

Gendeng Village, Baciro Village, Gondokusuman District, including urban areas in Yogyakarta. Infrastructure facilities generally are already good. The problems that exist in this community are the lack of facilities and public attention to artistic activities for children. So, this program aims to build a more integrated and sustainable child development system in the district / city dimension towards a child-friendly village. Methods of implementing the program include lecturing, practice, and coaching. The results and impacts of this activity are fulfilling children's rights to obtain information and art training that is fulfilled.

Keywords: empowerment, arts, child friendly 


\section{PENDAHULUAN}

Kampung Gendeng, Baciro, Gondokusuman terletak di tengah kota Yogyakarta. Dilihat dari sarana prasarana umumnya sudah baik. Profesi pekerjaan warganya mayoritas sebagai PNS dan buruh. Kesadaran warga akan pendidikan sangat tinggi. Sudah tersedia sarana pendidikan meliputi PAUD, TPA, Sekolah Dasar. Mayoritas warganya beragama Islam tetapi ada juga yang beragama Nasrani dan lainnya. Kerukunan antar warga yang berbeda agama dapat berjalan dengan baik. Permasalahan yang ada di kampung ini adalah kurangnya partisipasi warga masyarakat memberi ruang bagi anak-anak dalam berkesenian padahal kesenian sangat dibutuhkan dalam proses tumbuh kembang anak.

Plumer dalam Yulianti (2012) menjelaskan bahwa ada beberapa faktor yang mempengaruhi masyarakat untuk proses partisipasi yaitu salah satunya adalah pekerjaan masyarakat, biasanya orang dengan tingkat pekerjaan tertentu akan dapat lebih meluangkan ataupun bahkan tidak meluangkan sedikitpun waktunya untuk berpartisipasi pada suatu proyek tertentu. Seringkali alasan yang mendasar pada masyarakat adalah adanya pertentangan antara komitmen terhadap pekerjaan dengan keinginan untuk berpartisipasi.

Berdasarkan permasalahan di atas, mahasiswa KKN UAD menyelenggarakan berbagai kegiatan sesuai dengan kebutuhan warga masyarakat. UAD sebagai Perguruan Tinggi menyadari betul perlunya mahasiswa untuk berpartisipasi dalam bentuk pengabdian kepada masyarakat. Seperti yang dikemukakan Menteri PP-PA, Kementrian PP-PA (2016) menyebutkan bahwa menteri PP-PA Linda Amalia Sari Gumelar menghimbau Perguruan Tinggi pun ikut mengambil perannya dalam mendukung pemerintah dalam upaya pemenuhan hak anak melalui kampung ramah anak ini. "Perguruan tinggi mempunyai peran dalam melakukan Tri Dharma Perguruan Tinggi yang meliputi pengajaran, 
penelitian dan pengabdian pada masyarakat. Dengan melaksanakan fungsi tersebut diharapkan perguruan tinggi dapat mendukung pemerintah dan pemerintah daerah dalam melaksanakan penelitian atau kajian yang mendukung pada perumusan kebijakan tentang pemenuhan hak anak."

\section{METODE}

Metode menurut Sanjaya (2010) merupakan cara yang digunakan untuk mengimplementasikan sebuah rencana yang disusun sebelumnya dalam kegiatan nyata agar sesuai dengan tujuan awal dan berhasil secara optimal. Beberapa metode yang digunakan dalam kegiatan-kegiatan ini yaitu:

\section{Ceramah}

Metode ceramah digunakan untuk menyampaikan materi secara lisan atau verbal dengan media suara dan fasilitator. Dalam pelatihan ini metode ceramah digunakan ketika diawal sesi untuk menyampaikan materi secara umum.

\section{Praktek}

Metode ini merupakan salah satu upaya dalam memberikan pengalaman langsung kepada peserta. Metode ini digunakan pada saat kegiatan pelatihan setelah peserta mendapatkan teori.

Ringkasan metode pelaksanaan beserta jam kerja efektif mahasiswa (JKEM) dapat dilihat pada tabel di bawah ini. Kegiatan ini dilaksanakan selama dua hari pada tanggal 20-22 Mei 2018.

\begin{tabular}{|c|c|l|c|c|}
\hline No & Metode & \multicolumn{1}{|c|}{ Kegiatan } & JKEM & $\begin{array}{c}\sum \text { mhs } \\
\text { terlibat }\end{array}$ \\
\hline 1. & Praktek & Pelatihan Gerak lagu Islami & $1 \times 300^{\prime}$ & 27 \\
\hline 2. & Praktek & Pendampingan Belajar & $1 \times 100^{\prime}$ & 27 \\
\hline 3. & Ceramah dan & Pelatihan pembuatan kerajinan & $2 \times 100^{\prime}$ & 27 \\
\hline
\end{tabular}


2018 Jurnal Pemberdayaan: Publikasi Hasil Pengabdian kepada Masyarakat - ISSN: 2088 4559; e-ISSN:

\begin{tabular}{|l|l|l|l|l|}
\hline & Praktek & kreativitas tangan & \\
\hline 4. & Praktek & $\begin{array}{l}\text { Pembuatan taman bacaan } \\
\text { Pembacaan cerita Islami }\end{array}$ & $2 \times 150 \%$ & 27 \\
\hline
\end{tabular}

\section{HASIL, PEMBAHASAN, DAN DAMPAK}

Peraturan Kementrian Pemberdayaan Perempuan dan Perlindungan Anak Republik Indonesia Nomor 11 Tahun 2011 menjelaskan pengertian Kota Layak Anak/KLA adalah sistem pembangunan berbasis hak anak melalui pengintegrasian komitmen dan sumberdaya pemerintah, masyarakat dan dunia usaha yang terencana secara menyeluruh dan berkelanjutan dalam kebijakan, program dan kegiatan untuk menjamin terpenuhinya hak. Untuk menciptakan lingkungan yang baik tersebut, Linda mengatakan bahwa institusi yang dipimpinnya telah mengeluarkan Peraturan Menteri Nomor 6 Tahun 2013 tentang Pelaksanaan Pembangunan Keluarga dan juga kebijakan menuju Kabupaten/Kota Layak Anak (KLA). Tujuan kebijakan menuju pada kampung ramah anak antara lain untuk membangun sebuah sistem pembangunan anak yang lebih terintegrasi dan berkelanjutan dalam dimensi kabupaten/kota, sehingga percepatan pemenuhan hak-hak anak segera dapat dilakukan oleh semua pihak

Dalam proses tumbuh kembang, anak memiliki kebutuhan yang harus dipenuhi agar bisa bertumbuh kembang secara optimal. Kebutuhan tersebut bukan hanya terkait kebutuhan fisik, namun juga kebutuhan sosial dan psikologis, serta lingkungan yang mendukung berkembangnya semua potensi yang dimilikinya. "Lingkungan yang baik, akan menghasilkan anak yang baik yang selanjutnya akan berkembang menjadi insan dewasa dan berada di lingkungan yang lebih luas lagi, yaitu wilayah dan negara serta dunia. Kita tidak dapat mengharapkan adanya sumber daya manusia yang handal, jika lingkungan untuk anak tidak baik," ungkap Menteri PP-PA, Linda Amalia Sari Gumelar, dalam sebuah acara Talkshow.

Pemberdayaan Masyarakat Melalui Kampung Ramah Anak (Rina Ratih) | 154 
Kampung Gendeng, Baciro diakui sebagai rintisan kampung ramah anak. Keputusan ini berdasarkan pada rapat sosialisasi bulan September tahun 2014 di Balai RW 20. Keputusan ini diperkuat oleh Lucy Irawati sebagai Kepala KPMP Kota Y ogyakarta bahwa alasan KPMP menunjuk RW 20 sebagai Kampung Ramah Anak karena daerah tersebut telah menjunjung hak sipil dan kebebasan untuk anak, lingkungan, keluarga dan pengasuhan alternatif, hak kesehatan dasar dan kesejahteraan, pendidikan, hak perlindungan khusus, budaya serta sarana dan prasarana. Pembentukan kampung ramah anak ini sebagai upaya memenuhi hakhak dasar anak. Hak dasar yang dimiliki oleh anak-anak adalah bermain, berkreasi, berpartisipasi, berhubungan dengan orangtua bila dipisahkan, bebas berkumpul dan bergaul, hidup dengan orangtua, dan berhak untuk melangsungkan hidup, tumbuh, dan berkembang.

Kegiatan-kegiatan mahasiswa KKN UAD yang berlokasi di kampung Gendeng, Baciro ini mendukung terciptanya kampung ramah anak berupa pelatihan gerak lagu islami, pendampingan belajar, pendirian taman bacaan, pembacaan cerita Islami, dan pelatihan pembuatan kerajinan tangan.

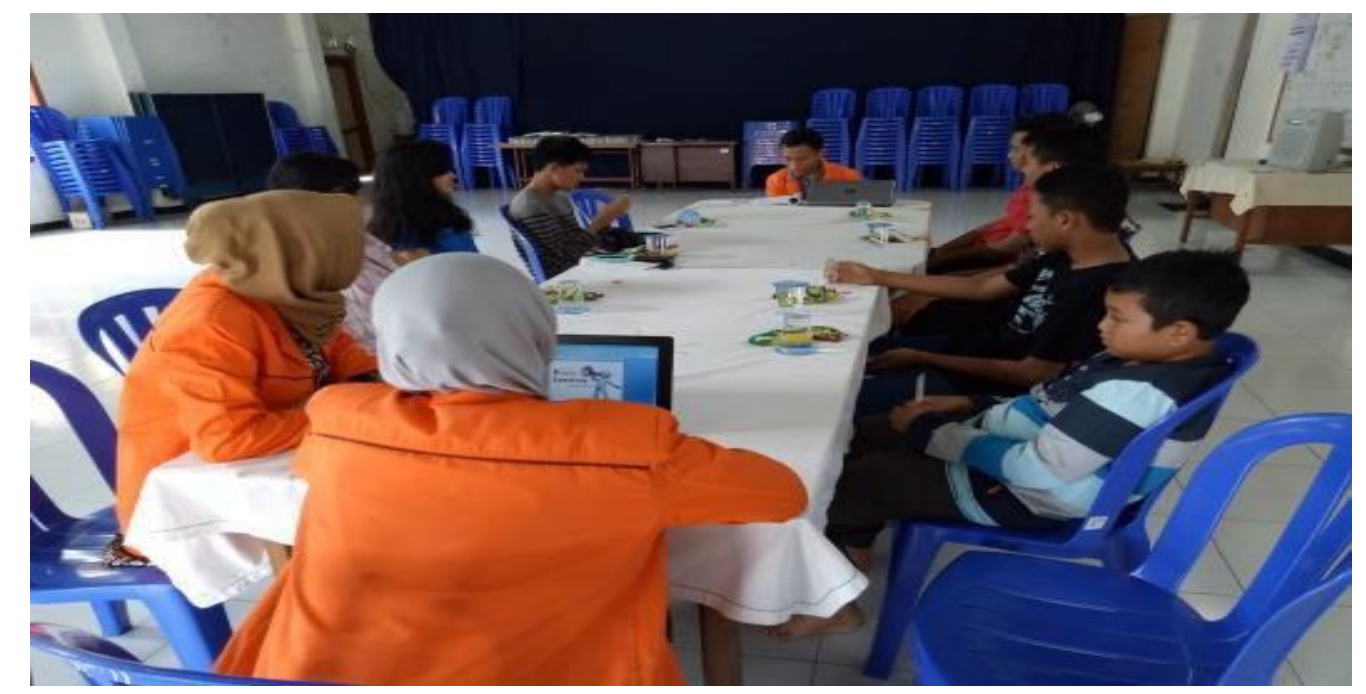

Gambar 1. Koordinasi kegiatan dengan pemuda

Mahasiswa KKN UAD mengundang remaja untuk berkoordinasi menyelenggarakan kegiatan-kegiatan yang mendukung kampung ramah anak. 
Koordinasi dengan remaja dilakukan agar kegiatan yang sudah direncanakan dapat berjalan dengan baik.

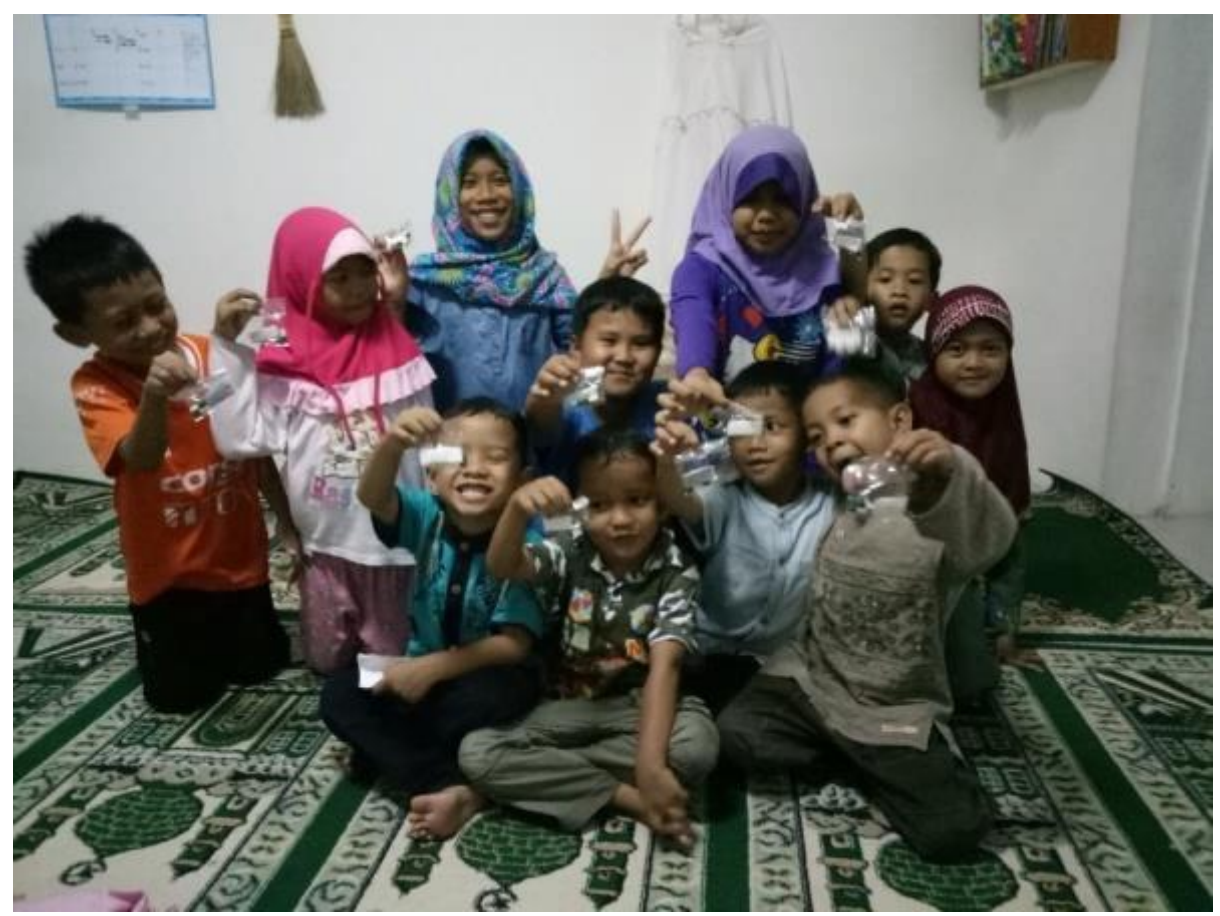

Gambar 2. KKN UAD dalam pendampingan terhadap anak-anak

Mahasiswa KKN UAD mendampingi anak-anak untuk pendampingan belajar, membacakan cerita-cerita Islami, dan memberi pelatihan kreativitas kerajinan tangan. 


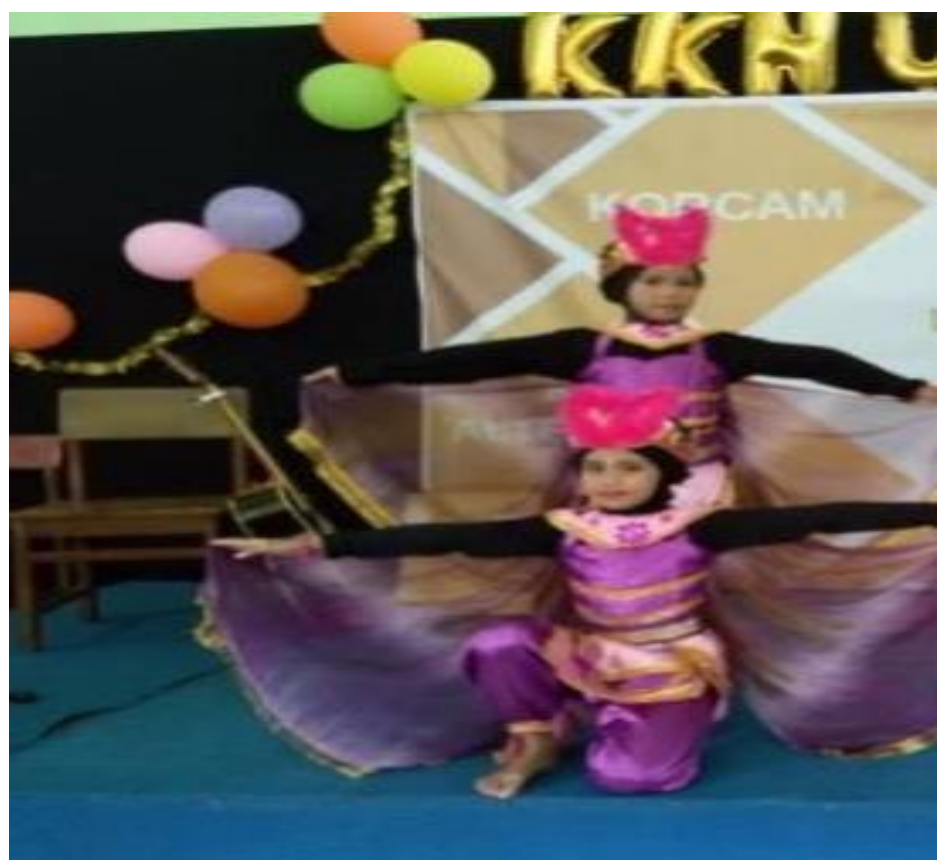

Gambar 3. Pendampingan pelatihan gerak dan lagu

Mahasiswa KKN UAD memberikan pendampingan pelatihan gerak lagu Islami untuk anak-anak kemudian diikutkan pada lomba Gerak lagu di tingkat Kecamatan Bausastran. Dampak dari kegiatan-kegiatan yang sudah dilakukan adalah terciptakan suasana belajar dan berkesenian lebih kondusif di kampung Gendeng, Baciro, Yogyakarta ini.

\section{SIMPULAN}

Kegiatan-kegiatan yang sudah terlaksana dan mendukung terciptanya kampung ramah anak yaitu pelatihan gerak lagu islami, pendampingan belajar, pendirian taman bacaan, pembacaan cerita Islami, dan pelatihan pembuatan kerajinan tangan. Kegiatan-kegiatan tersebut mendapat apresiasi, baik dari anakanak maupun orang tua. Kiprah anak-anak berkesenian tampak memperkuat Kelurahan Baciro sebagai kampung ramah anak. 


\section{DAFTAR PUSTAKA}

Kementrian PP-PA. 2016. Menteri PP-PA Tekankan Pentingnya Kampung Ramah Anak. Diakses dari: https://www.kemenpppa.go.id/index.php/page/read/30/468/menteri-pp-patekankan-pentingnya-kampung-ramah-anak Yogyakarta. Tanggal 26 Januari 2019.

Peraturan Kementrian Negara Pemberdayaan Perempuan dan Perlindungan Anak Republik Indonesia Nomor 11 Tahun 2011 (Tentang Kebijakan/Pengembangan Kota Layak Anak).

Sanjaya, W. 2010. Strategi Pembelajaran Berorientasi Standar Proses Pendidikan. Jakarta: Kencana

Yulianti, Y. 2012. Analisis Partisipasi Masyarakat dalam Pelaksanaan Program Nasional Pemberdayaan Masyaarakat (PNPM) Mandiri Perkotaan. Padang : Universitas Andalas. 